\title{
DEVIATION PATTERNS OF OBSERVED AND EXPECTED HAPLOTYPE BLOCKS ASSOCIATED WITH POTENTIAL RECESSIVE DISORDERS IN TYROL GREY CATTLE
}

\author{
Maulana Naji¹, Cord Drögemüller², Gábor Mészáros¹, Johann Sölkner \\ ${ }^{1}$ Division of Livestock Sciences, Department of Sustainable Agricultural Systems, University of Natural Resources \\ and Life Sciences, Gregor-Mendel-Str. 33, A-1180 Vienna, Austria \\ ${ }^{2}$ Institute of Genetics, Vetsuisse faculty, University of Bern, Bremgartenstrasse 109a, 3001 Bern, Switzerland
}

To link to this article: https://doi.org/10.11118/actaun201967051183

Received: 22. 7. 2019, Accepted: 23. 8. 2019

To cite this article: NAJI MAULANA, DRÖGEMÜLLER CORD, MÉSZÁROS GÁBOR, SÖLKNER JOHANN. 2019. Deviation Patterns of Observed and Expected Haplotype Blocks Associated with Potential Recessive Disorders in Tyrol Grey Cattle. Acta Universitatis Agriculturae et Silviculturae Mendelianae Brunensis, 67(5): 1183-1188.

\begin{abstract}
Confirmed by phenotypic records, several studies across different breeds in different locations have linked missing homozygous pattern with several defects in the functional system and recessive genetic disorders. Recessive genetic diseases are expressed when the recessive alleles appear in a homozygous state for an individual. One of the indicators to detect the recessive allele is through haplotypes, which have a normal frequency in the population, but never occur in the homozygous state. In this study, we used SNP genotypes of 220 Austrian Tyrol Grey cattle and 80 Italian Tyrol Grey cattle to identify the haplotype blocks (Hapblocks) that possibly carry genes causing recessive disorders. Hapblocks with missing homozygous state in the population were statistically tested as to whether this is very unlikely in Hardy-Weinberg equilibrium. Eight out of all hapblocks passing the threshold had functional genes which are crucial in maintaining the metabolism, production, reproduction, and health of the individuals. These hapblocks had a high frequency of above $13 \%$ but never appear in homozygous state. Thus, these are foreseen as potential source of genetic defects. Our finding in this analysis can be used as a reference for further study in haplotype analyses of inherited recessive disease for other cattle breeds.
\end{abstract}

Keywords: recessive disease, haplotype, missing homozygous, Tyrol Grey cattle

\section{INTRODUCTION}

The recessive disorder can manifest itself if the haplotypes carrying harmful recessive alleles get in the homozygous state. As a result, the onset of the defects can happen during embryonic, pregnancy, or post-natal stages leading to lethal or non-lethal risks. In the population, the recessive haplotype appears in normal frequency, but almost never occur in a homozygous form in the healthy individual. The existence of this haplotype in the population is due to carrier animals which are heterozygous and not directly affected (Sahana et al., 2013).

Finding the causal variants for recessive disorders has became feasible through missing homozygous haplotype pattern in population with the availability of genotyping method using Single Nucleotide Polymorphism (SNP) chips. Confirmed by supportive information of pedigrees and phenotypic records, the pattern of haplotypes can be inferred that never appear in the homozygous state. 
Several haplotypes were linked to recessive disease in USA dairy population (VanRaden et al., 2011). Posit haplotypes corresponding to Holstein, Jersey, and Brown Swiss, had reduced the conception rate by $3.2,3.7$ and 3.4 percent, respectively. It also increased the percentage of stillbirth calves up to 1.8 percent in the Holstein breed. As reported by Fritz et al. (2013), the similar adverse effects towards calving rate, up to $-9.89 \%$, were also detected in Holstein, Montbeliarde and Normande in the French population. In addition, a study utilizing Next Generation Sequencing (NGS) data supported the linkage between missing homozygous haplotypes with embryonic lethal variants compromising fertility in Belgian beef and New Zealand dairy cattle (Charlier et al., 2016).

In Tyrol Grey Cattle, 31 cases of calves, aged of 3-5 months, with degenerative axonopathy having nervous system defect leading to unstable movement and losing control of hinder part of the body have been reported (Drogemuller et al., 2011; Sölkner et al., 2009). Genome-wide association study (GWAS) and haplotype mapping were carried out investigating the causal reason. They found haplotype carrying a silent SNP within MFN2 gene was associated with the onset of this defect. Murgiano et al. (2014) found chondrodysplasia dwarfism in seven calves, aged of one week to 2.5 months. The affected animals had shorter limbs with twisted femur bones causing difficulty to maintain the quadrupedal stance. Another case, identified homozygosity of haplotype carrying one bp deletion in the MOCOS gene causing reinal failure (Xanthinuria) with uroliths deposit in the kidney of affected animals (Murgiano et al., 2016).

Due to previous studies associating several recessive defects with missing homozygous haplotype pattern which confirmed by the phenotypic records and pedigrees. We carried out the similar procedure to predict possible hidden defects in our dataset of Tyrol Grey cattle without using phenotypic records. With our genotype dataset presuming all genotyped animals were in the state of normal health, we analyzed the missing homozygous pattern based on observed and expected homozygous counts to find haplotypes associated with known defects.

\section{MATERIALS AND METHODS}

Genotyped data were provided by University of Natural Resources and Life Sciences, Vienna, and the University of Bern from previous projects, therefore animal health and welfare permission was not necessary for the current study. Genotyped data were comprised of 100 Illumina Bovine SNP 50K v1 and 120 Illumina Bovine SNP HD of Austrian Tyrol Grey cattle, and 48 Illumina Bovine SNP 50K v2 and 32 Illumina Bovine SNP HD of Italian Tyrol Grey cattle.
Merging the data sets was carried out referring to all markers in Bovine Taurus Autosomal (BTA) 1-29 of Illumina Bovine SNP 50K v1 by using PLINK software (Purcell and Chang, 2017), discarding other markers which not found in the reference SNP chip. Applied standard quality control kept only individuals and SNP markers with call rates higher than 0.9, with no limitation on minor allele frequency and Hardy-Weinberg equilibrium parameters. In the remaining dataset, 276 cattle with 44035 markers were retained corresponding to a total genotyping rate of 0.966 .

Phasing and statistical haplotypes estimation steps were carried out using SHAPEIT2 software (Delaneau et al., 2017). For correcting markers with overlapping physical position, adding a single base was implemented for the second same marker. This software generated two output files with the extension of (.hap) and (.sample). To fit for the next procedure, it was converted into (.phase), (.samples), and (.markers) using Unix code provided by the GHap authors.

The GHap package (Utsunomiya and Milanesi, 2017) in R software was used to call block of haplotypes (Hapblock) from phased SNP data and to calculate its observed and expected homozygous haplotype numbers. Hapblocks were generated by scanning window of $500 \mathrm{~kb}$ and sliding step every $100 \mathrm{~kb}$. Generated hapblock was the result of the possible combination of allele markers within the window. The expected homozygous (E.Hom) was calculated following function of sample size (n) and the frequency of the hapblock in population (p).

E.Hom $=n p^{2}$.

QQman package in $\mathrm{R}$ was used to visualize the peak of hapblocks significance in Manhattan plots. The significance was calculated based on the deviation of observed from the expected hapblocks. Physical regions of hapblocks passing the threshold of P-value were annotated towards gene functions using reference genome of Bos Taurus UMD 3.1.1 on NCBI database.

\section{RESULTS}

In this study, we generated 704,550 hapblocks across 29 BTA. They were generated based on the allele combinations of markers within the scanning window. As seen in figure1, hapblocks were represented as points across the genome. Ninety-three hapblocks with missing or less homozygous genotypes passed threshold of P-value. Physical regions of these hapblocks were further investigated to link with harbored gene functions. All dots below the threshold, indicating statistically concordance between expected and observed homozygous haplotypes.

The eight hapblocks out of ninety-three passing the threshold have functional genes as listed in 


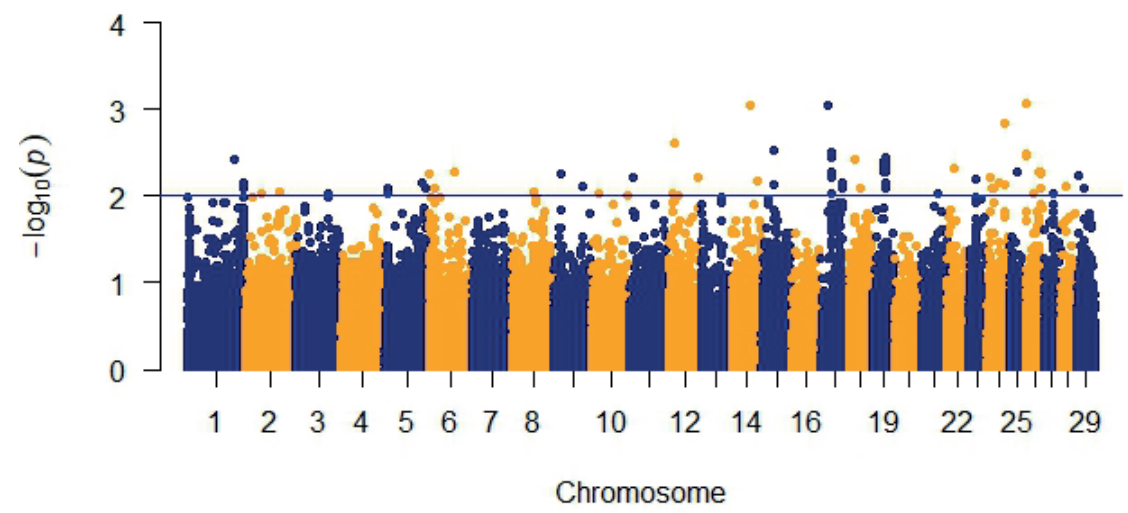

1: Haplotype blocks with lower observed than expected homozygous

I: Hapblocks list with annotated functional genes

\begin{tabular}{|c|c|c|c|c|c|c|c|c|c|c|c|}
\hline CHR & $\begin{array}{c}\text { BP1 } \\
(\mathrm{Mb}) \\
\end{array}$ & $\begin{array}{c}\text { BP2 } \\
(\mathrm{Mb}) \\
\end{array}$ & ALLELE & $\mathrm{N}$ & FREQ & O.HOM & O.HET & E.HOM & RATIO & P-Val & Genes \\
\hline 3 & 89.6 & 90.1 & BAABABBBBBBAB & 72 & 0.13 & 0 & 72 & 4.70 & 5.70 & 0.0091 & PRKAA2 \\
\hline 5 & 99.9 & 100.4 & $\mathrm{ABBAB}$ & 99 & 0.18 & 2 & 95 & 8.88 & 3.29 & 0.0069 & OLR1, CLEC7A \\
\hline 12 & 18.3 & 18.8 & $\mathrm{ABBB}$ & 163 & 0.30 & 11 & 141 & 24.07 & 2.09 & 0.0024 & CYSLTR2 \\
\hline 15 & 35.5 & 36.0 & BAAABBBABBAAABB & 88 & 0.16 & 1 & 86 & 7.01 & 4.01 & 0.0072 & KCNJ11, NUCB2 \\
\hline 19 & 33.8 & 34.3 & AABABBBBBB & 76 & 0.14 & 0 & 76 & 5.23 & 6.23 & 0.0053 & ADORA2B \\
\hline 19 & 34.8 & 35.3 & BBAAAAABBB & 77 & 0.14 & 0 & 77 & 5.37 & 6.37 & 0.0047 & SLC5A10, SREBP1 \\
\hline 19 & 36.3 & 36.8 & BABABBABBBB & 74 & 0.13 & 0 & 74 & 4.96 & 5.96 & 0.0070 & CACNA1G \\
\hline 26 & 39.7 & 40.2 & AABABBBAAA & 76 & 0.14 & 0 & 76 & 5.23 & 6.23 & 0.0053 & GRK5 \\
\hline
\end{tabular}

Tab. I. The number of alleles for each hapblock can be different due to the number of markers found within the $500 \mathrm{~kb}$ scanning window. These eight hapblocks are observed 72 to 163 times in the population (N) and corresponding to frequency of 0.13 to 0.30 as seen in column (FREQ).

We found one, three and one hapblocks with missing homozygous genotypes in chromosome three, nineteen, and twenty-six, respectively. The average shrinkage ratio expected-to-observed number of homozygotes for these five hapblocks is 6.1. This mean homozygosity for these hapblocks are 6 times less observed than what expected. Meanwhile three hapblocks were found in chromosome five, twelve, and fifteen, with less observed homozygous genotypes than what expected. The average shrinkage ratio for these three hapblocks is 3.1, almost half of the expectation for those with missing homozygous genotypes.

Genes found within regions of these hapblocks are remarkable importance for metabolism. The functions of genes will be explained briefly here. PRKAA2 gene, which is encoding the a2 catalytic subunit of the AMP-activated kinase (AMPK) regulating the metabolism of glucose and fatty acid (Zhang et al., 2011). The product of OLR1 gene has a functional role in preventing the damage of the arterial endothelium by degrading the bad cholesterol, i.e., oxidized low-density lipoprotein (LDL). Due to its function in lipid metabolism activity, polymorphism in 3' UTR of this gene is also associated with meat marbling and milk production (Wang et al., 2013). A variant of amino acid from CLEC7A, SNP c.589A $>$ G, encodes bovine Dectin-1 which together with Toll-like receptor (TLR) can provoke a proinflammatory response towards Mycobacterium sp. infection (Pant et al., 2014). An amino acid produced by CYSLTR2 gene is a leukotrienes receptor for LTC4. The LTC4 function is to stimulate PGF2a secretion at the end of regular reproduction cycle of cattle (Korzekwa et al., 2016). Different allele expression of KCNJ11 gene has a potential impact on the phenotypic variation of meat properties, i.e. tenderness, as found in Nellore beef cattle (de Souza et al., 2016). Polymorphism of NUCB2 gene in Chinese cattle breeds are associated with growth traits, including body weight, body length, heart girth, and average daily gain at 24 months (Li et al., 2010). Receptor from $A D O R A 2 B$ gene is required for the purinergic stimulation of cilia beat frequency, a mechanism which is vital for the lung clearance and part of pulmonary defense (Allen-Gipson et al., 2011). Expression of SLC5A10 gene from SGLT family is primarily found in kidney, because it is essential for transporting elements like sodium and glucose 
against the electrochemical gradient (Zhao et al., 2005). SREBP1 gene has an important role in the biosynthesis of fatty acids and cholesterol and lipid metabolism. The polymorphism of this gene affects the fatty acids composition of muscle and carcass in Simmental bulls (Xu et al., 2013). CACNA1G gene has wide effects on cellular levels towards the physiological process. The process is including neuronal excitability, muscle excitation and contraction (Walsh et al., 2009). GRK5 gene plays a role in the cardiac signaling events. The expression of this gene is profoundly in the heart and is responsible for pathological hypertrophic transcription (Hullmann et al., 2014).

\section{DISCUSSION}

The expected homozygosity in our study is a function of sample numbers multiplied by the square of the frequency of that hapblocks in the sample population. Expected number of homozygous will increase following the number of genotyped animals in the study. Our expectation of homozygosity is at maximum of 24.07 for hapblock CHR12_B169 as indicated in column (E.HOM). While expectation in other studies are higher such 30 for HH1, 33 for HH2, 131 for MH1, and 26 for MH10 in two Holstein and two Montbeliarde populations, respectively (VanRaden et al., 2011; Fritz et al., 2013). These two studies had a higher expectation for homozygosity due to a larger dataset compared to ours. Studies carried out by Vanraden et al. (2011) used 58,453 genotyped animals in USA Holstein population and Fritz et al. (2013) used 16,833 genotyped animals in French Montbeliarde population. While in our study, a small number of 300 genotyped animals leads to a more modest expectation of homozygosity for the hapblocks.

Increasing numbers of genotyped animals can lead to either of two consequences towards the missing homozygous hapblocks. First, frequency of hapblocks will increase in the population with still no homozygous animals. Thus, it makes the evidence that the hapblock indeed carrying recessive alleles. Second, increased number of genotyped animals brings several homozygous animals for that suspected missing homozygous hapblocks eventually. Thus, missing homozygosity for that hapblocks is simply due to low number of genotyped animals.

Generating thousands of genotyped animals from the whole population for Tyrol Grey breed is not feasible. Not only because genomic data is not widespread yet in the genetic management system of this breed, but also, due to the fact that this only a small breed with 18,096 Tyrol Grey cattle in 2017, 0.9\% Austrian population. (Kalcher et al., 2018).

Number of observations (N) for these eight hapblocks, was at least observed 72 times in the population with the frequency is ranging from 13 to 30 percent (FREQ). The hapblock frequency was relatively higher than those in previous studies, such for MH10 (2.5\%), and NH1 (18\%) in Montbeliarde and Normande breeds, respectively (Fritz et al., 2013). A higher frequency of hapblocks found in this study, which were missing in homozygous form points to potential hidden disorders caused by mutations of genes lying in these particular regions.

Due to the hapblocks frequency of higher than $13 \%$ with no observed homozygous, we were suspecting these hapblocks carrying a harmful mutant allele. If such harmful mutation occurs, it could lead to change in the gene's transcription, and in turn, lead to dysfunction of the organism. Therefore, in a healthy individual, we could not see these hapblocks in a homozygous state. Nevertheless, we foresee these hapblocks as a potential source of defects and new recessive disorders.

Verification of haploblocks with missing homozygous linked to negative or positive effect of those genes are not viable due to limitation in phenotypes. Interestingly we did not detect regions with already known recessive defects particularly those been found in Tyrol Grey cattle, i.e., chondrodysplasia dwarfism, xanthinuria, and degenerative axonopathy. In assumption that hapblocks carried recessive alleles are relatively high in frequency, but never occur in homozygous state in healthy individuals. Thus, our founding suggests that hapblocks carrying previously known recessive alleles are not frequent in the population of Tyrol Grey population.

\section{CONCLUSION}

In this study, we detected deviation pattern of observed hapblocks from what was expected with scanning window of $500 \mathrm{~kb}$ of the Tyrol Grey cattle genome. We detected hapblocks with missing homozygous pattern pointing out several essential functional genes. Many of the genes were linked to essential metabolic processes, thus these genomic regions could be foreseen as potential source of genetic defects. Interestingly, we could not find any missing homozygous hapblocks linked to the already known recessive diseases.

Acknowledgements

Maulana Naji was granted Erasmus Mundus Alfabet for his MSc and currently receiving Ernst Mach Grant PhD scholarship from OeAD GmbH. 


\section{REFERENCES}

ALLEN-GIPSON, D. S., BLACKBURN, M. R., SCHNEIDER, D. J., ZHANG, H., BLUITT, D. L., JARRELL, J. C., YANOV, D., SISSON, J. H. and WYATT, T. A. 2011. Adenosine activation of A(2B) receptor(s) is essential for stimulated epithelial ciliary motility and clearance. Am. J. Physiol. Lung Cell. Mol. Physiol., 301(2): L171-L180.

CHARLIER, C., LI, W., HARLAND, C., LITTLEJOHN, M., COPPIETERS, W., CREAGH, F., DAVIS, S., DRUET, T., FAUX, P., GUILlAUME, F., KARIM, L., KEEHAN, M., KADRI, N. K., TAMMA, N., SPELMAN, R. and GEORGES, M. 2016. NGS-based reverse genetic screen for common embryonic lethal mutations compromising fertility in livestock. Genome Res., 26: 1333-1341.

DE SOUZA, M. M., NICIURA, S. C. M., TIZIOTO, P. C., IBELLI, A. M. G., GASPARIN, G., ROCHA, M. I. P., BRESSANI, F. A., MALAGO-JR, W., DINIZ, W. J. S., DE OLIVEIRA, P. S. N., LIMA, A. O., MUDADU, M. A., BARIONI JUNIOR, W., COUTINHO, L. L. and REGITANO, L. C. A. 2016. Allele- and parent-of-originspecific effects on expression of the KCNJ11 gene: A candidate for meat tenderness in cattle. Genet. Mol. Res., 15(3): gmr.15038549.

DELANEAU, O., HOWIE, B., COX, A. J., ZAGURY, J.-F. and MARCHINI, J. 2017. Haplotype Estimation Using Sequencing Reads. Am. J. Hum. Genet., 93(4): 687-696.

DROGEMULLER, C., REICHART, U., SEUBERLICH, T., OEVERMANN, A., BAUMGARTNER, M., KUHNI BOGHENBOR, K., STOFFEL, M. H., SYRING, C., MEYLAN, M., MULLER, S., MULLER, M., GREDLER, B., SOLKNER, J. and LEEB, T. 2011. An unusual splice defect in the mitofusin 2 gene (MFN2) is associated with degenerative axonopathy in Tyrolean Grey cattle. PloS One, 6(4): e18931.

FRITZ, S., CAPITAN, A., DJARI, A., RODRIGUEZ, S. C., BARBAT, A., BAUR, A., GROHS, C., WEISS, B., BOUSSAHA, M., ESQUERRÉ, D., KLOPP, C., ROCHA, D. and BOICHARD, D. 2013. Detection of Haplotypes Associated with Prenatal Death in Dairy Cattle and Identification of Deleterious Mutations in GART, SHBG and SLC37A2. PLOS ONE, 8(6): e65550.

HULLMANN, J. E., GRISANTI, L. A., MAKAREWICH, C. A., GAO, E., GOLD, J. I., CHUPRUN, J. K., TILLEY, D. G., HOUSER, S. R. and KOCH, W. J. 2014. GRK5-mediated exacerbation of pathological cardiac hypertrophy involves facilitation of nuclear NFAT activity. Circ. Res., 115: 976-985.

KALCHER, L., FÜRST, C. and EGGER-DANNER, C. 2018. Zentrale Arbeitsgemeinschaft österreichischer Rinderzüc: Jahresbericht 2017. Ried im Innkreis: Hammerer.

KORZEKWA, A. J., MILEWSKI, R., LUPICKA, M. and SKARZYNSKI, D. J. 2016. Leukotriene production profiles and actions in the bovine endometrium during the oestrous cycle. Reprod. Fertil. Dev., 28(6): 682-689.

LI, F., CHEN, H., LEI, C. Z., REN, G., WANG, J., LI, Z. J. and WANG, J. Q. 2010. Novel SNPs of the bovine NUCB2 gene and their association with growth traits in three native Chinese cattle breeds. Mol. Biol. Rep., 37(1): 541-546.

MURGIANO, L., JAGANNATHAN, V., BENAZZI, C., BOLCATO, M., BRUNETTI, B., MUSCATELLO, L. V., DITTMER, K., PIFFER, C., GENTILE, A. and DROGEMULLER, C. 2014. Deletion in the EVC2 gene causes chondrodysplastic dwarfism in Tyrolean Grey cattle. PloS One 9(7): e94861.

MURGIANO, L., JAGANNATHAN, V., PIFFER, C., DIEZ-PRIETO, I., BOLCATO, M., GENTILE, A. and DRÖGEMÜLLER, C. 2016. A frameshift mutation in MOCOS is associated with familial renal syndrome (xanthinuria) in Tyrolean Grey cattle. BMC Vet. Res., 12: 276.

PANT, S. D., VERSCHOOR, C. P., SCHENKEL, F. S., YOU, Q., KELTON, D. F. and KARROW, N. A. 2014. Bovine CLEC7A genetic variants and their association with seropositivity in Johne's disease ELISA. Gene, 537(2): 302-307.

PURCELL, S. and CHANG, C. 2017. PLINK [version]. [Program]. Copyright Christopher Chang.

SAHANA, G., NIELSEN, U. S., AAMAND, G. P., LUND, M. S. and GULDBRANDTSEN, B. 2013. Novel harmful recessive haplotypes identified for fertility traits in Nordic Holstein cattle. PLoS ONE, 8(8): e82909.

SÖLKNER, J., GREDLER, B., DRÖGEMÜLLER, C. and LEEB, T. 2009. Homozygosity mapping of a weaver-like disorder in Tyrol Grey cattle. In: Annual Conference of the European Association for Animal Production. August $24^{\text {th }}-27^{\text {th }}$. Barcelona, Spain.

UTSUNOMIYA, Y. T. and MILANESI, M. 2017. Package package for genome-wide haplotyping GHap. [Program].

VAN RADEN, P. M., OLSON, K. M., NULL, D. J. and HUTCHISON, J. L. 2011. Harmful recessive effects on fertility detected by absence of homozygous haplotypes. J. Dairy Sci., 94(12): 6153-6161.

WALSH, C. P., DAVIES, A., BUTCHER, A. I., DOLPHIN, A. C. and KITMITTO, A. 2009. Three-dimensional structure of CaV3.1: comparison with the cardiac L-type voltage-gated calcium channel monomer architecture. J. Biol. Chem., 284: 22310-22321. 
WANG, X., LI, T., ZHAO, H. B. and KHATIB, H. 2013. Short communication: A mutation in the 3' untranslated region diminishes microRNA binding and alters expression of the OLR1 gene. J. Dairy Sci., 96(10): 6525-6528.

XU, L., ZHANG, L. P., YUAN, Z. R., GUO, L. P., ZHU, M., GAO, X., GAO, H. J., LI, J. Y. and XU, S. Z. 2013. Polymorphism of SREBP1 is associated with beef fatty acid composition in Simmental bulls. Genet. Mol. Res., GMR 12(4): 5802-5809.

ZHANG, Q., ZHAO, S., CHEN, H., ZHANG, L., ZHANG, L., LI, F. and WANG, X. 2011. SNP discovery and haplotype analysis in the bovine PRKAA2 gene. Mol. Biol. Rep., 38(3): 1551-1556.

ZHAO, F.-Q., ZHENG, Y.-C., WALL, E. H. and MCFADDEN, T. B. 2005. Cloning and expression of bovine sodium/glucose cotransporters. J. Dairy Sci., 88(1): 182-194.

Maulana Naji: agis.maulana12@gmail.com Cord Drögemüller: cord.droegemueller@vetsuisse.unibe.ch Gábor Mészáros: gabor.meszaros@boku.ac.at Johann Sölkner: johann.soelkner@boku.ac.at 